\title{
Family Violence Resolution Strategies. \\ Legal Prevention and Education Against Ignorance
}

\author{
Prof. Firuza Mukhitdinova, PhD
}

Tashkent State University of Law, Uzbekistan

\section{Abstract}

The article analyses the strategies for reducing the phenomena of domestic violence, focusing on the legal preventive measures. It highlights the historical aspects of the problem, by referring to the legal framework, in trying to overcome it. By introducing the causes and the nature of the domestic violence in Uzbekistan, leveraging into a theoretical, historical and legal analysis, social measures are weighted in relation to the domestic violence. The methodological approaches in the study of social processes of domestic violence are used meanwhile evaluating the social consequences of domestic violence, considering the correlation between the increased instability in the society and the level of social dissatisfaction of the population. The paper, by referring to the Laws of the Republic of Uzbekistan "On the Protection of Women from Oppression and Violence", as well as to several other laws and regulations on regard, makes a review to the reforms and notebooks such as "iron notebook", "youth" and "women", where special attention is paid to the correlations between unemployment of youth and women and the phenomena of domestic violence.

Keywords: iron notebook; youth notebook; youth; women's notebook; problems of domestic violence; law; protection; rights; Uzbekistan.

This function includes, first of all, relying on the activists of makhallas, respected veterans with extensive life experience of venerable mothers, on your dear women, knowledge and spiritual potential.

Shavkat Mirziyoyev

\section{Introduction}

From November 25 of year 2021, the campaign "16 days of active actions against gender-based violence" has been announced in Uzbekistan. A series of meetings and events are held to clarify women's rights: the essence of laws, regulations in support of women. Since November 25 is the International Day for the Elimination of Violence against Women under the Council of Europe Convention on Preventing and Combating Violence against Women and Domestic Violence. Since 1990, the Council of Europe has actively advocated for the protection of women and girls from gender-based violence, in particular through the adoption of Recommendation 5 (2002) on the protection of women from violence, and through the implementation of a pan-European campaign to combat violence against women, 
including violence in the family, the Council of Europe's New Convention on Preventing and Combating Violence against Women and Domestic Violence is the most progressive international treaty addressing this grave violation of human rights. The Convention aims to create a "zero tolerance" for this form of violence and represents a critical step towards making Europe and other regions a safer place to live.

It also explains the main innovation of the decree adopted in May 2021 "On additional measures for the rehabilitation of women victims of violence", aimed at creating a system for providing assistance to women who have been subjected to violence, preventing and eliminating the negative consequences of family and domestic violence. 29 centers for the rehabilitation and adaptation of women, financed from the state budget ${ }^{1}$, have been created, as well as for the provision of prompt psychological and legal assistance, counseling and information to women who have suffered from oppression and violence, today a hotline " 1146 " is already operating. Events as the one at the Republican Center for Spirituality and Enlightenment, at SamPI, a financial institution, at the Tashkent State Economic University evidenced the interest in reports focusing in the rights guaranteed by the state.

\section{Methodology: the methodological basis of the study is system analysis,}

The relevance and purpose of the article is determined by:

- Firstly, the scale of the prevalence of violence in families and its consequences at all levels - from the individual to society as a whole.

- Secondly, - the need for scientific understanding of this problem in order to prevent all aspects of its manifestation and achieve a reduction;

- Thirdly, the practical need to develop an approach in New Uzbekistan to the prevention, overcoming and regulation of social processes of domestic violence.

\section{Discussion}

The spread of humanistic relations in the modern world has significantly influenced the reassessment of the socio-cultural norms of interpersonal and intergroup interaction. Respect for a person's personality, tolerance, orientation towards cooperation are becoming the priority goals of the development of social subjects. In Uzbekistan, as in other countries, conditions are being created for the establishment of the principles and ideals of humanism in the daily life of people, and significant changes have already been achieved in some spheres of society. In September 2019, Uzbekistan adopted the Law of the Republic of Uzbekistan "On the Protection of Women from Oppression and Violence." In order to implement this Law, on January 4, 2020, by a resolution of the Cabinet of Ministers "On measures to improve the system of protecting women from

${ }^{1}$ Republic of Uzbekistan, Year 2021 
oppression and violence", a number of documents were approved that are necessary to ensure the safety of women. In particular, a procedure has been developed for obtaining a protection order that provides state protection to women and girls who have suffered from harassment and violence. Today, in the fight against domestic violence, it is important to use modern means of communication that allow you to receive help without leaving your home. Thus, on the initiative of the Commission on Ensuring Gender Equality, the Telegram channel "No to Violence!" was aired, in order to prevent cases of domestic violence. Thanks to it, women and girls received free legal advice and psychological assistance. However, the social security of the individual continues to be an acute social problem. In modern society, there are various social norms, some of which prohibit violence against any person, others allow and justify it. On the one hand, humanistic ideas about relations between people lead to the assertion of orientations towards tolerance, respect for the individual, the need to resolve emerging conflicts in non-violent ways. At the same time, the norms for resolving controversial situations dealing with various forms of violence that have arisen at the initial stages of the historical development of society are preserved. There are also currently the use of economic coercion, psychological influence, the use of some forms of violence against women and children in the family. Even if there is a strong will and there are attempts to diminish incidences of domestic violence, this is the most important problem in society. It is required to develop an integrated approach to defining the essence of domestic violence, the main forms of its manifestation, objective and subjective factors leading to the emergence of violence in conflict situations between representatives of different gender communities. Thus, in todays Uzbekistan, when the country joined the UN Human Rights Council, the theoretician becomes even more relevant. The legal analysis of domestic violence is determined by the existing contradictions in the system of relations, leading to the emergence of severe coercion in resolving conflict situations in a modern family. At present, the situation remains ignorant of the very need for a deep and comprehensive scientific study of domestic violence, which was constantly reproduced in the past and is still present in a certain part of families. In modern society, there remains a need to study the problem of domestic violence, especially in relation to women. Many legal scholarships do not deeply reveal the historical and social basis for the spread of domestic violence. In them, the main attention is focused only on the study of the personal characteristics of the subjects and objects of violence. The importance of analyzing this problem lies in the fact that violence is an interaction not only between the subject and the object of violence, but also between social groups and communities that in one form or another allow the use of violence. Citing the Koran, the rights of mothers and the proper attitude of children to mothers are mentioned in several suras of the Holy Book, which speak of the rights of our mothers and fathers. One of the hadiths says: "(Once) a man came to the Messenger of Allah (peace and blessings of Allaah be upon him) and asked: 'O Messenger of Allah, which of the people is most 
worthy that I be good with him got along? " He said, "Your mother." (This person) asked: "Then who?" He said, "Your mother." (The man) asked: "Then who?" He said, "Your mother." (The man again) asked, "Then who?" (And then) he said (to him): "Your father." It does not say that the rights of fathers are placed below the rights of mothers. By following up this line of thougt on the history of political and legal doctrines, it helps highlighting the following statements attributed to the Prophet Muhammad: "Everything that is created by the Almighty in this world is priceless and the most priceless among them is a woman. And according to the views of Omar Hayam, we read that, "I asked the priest:" Father, tell me, where is heaven on earth? Show the way there, how to go there, give me some landmarks? "The priest answered: "The path, son, you choose yourself. Paradise is at your mother's feet! "Motherhood is the highest form of a woman's patriotism: to serve her Fatherland through the education of wonderful people. This is the most important creative profession on Earth, in which a woman can realize herself as a person, and this is her genius and morality. Woman is nature itself, it is not only a mother, wife, sister, daughter, leader, but also the keeper of the family hearth, the successor of the human race, a symbol of wisdom, beauty, femininity, fidelity, stability, love of the people. "Mama!" - the first word of a child, which is sacred among all peoples of the world. Everyone knows that any social culture is based on a system of positive values, which is based on a positive image of a person. And the obligatory image on which a sustainable culture rests is a positive image of a woman as a mother. The destruction of this image alone entails the destruction of the entire culture and the degradation of society. How many works in the history of the development of mankind were dedicated to women - how many poets, composers, artists sang the image of the mother. A mother woman is the most important person in the life of each of us. Genius women were very different from each other. For example Tomaris - the woman who protected the ancient Turan from Cyrus II. Tekinakhanum is the mother of Amir Timur, Bibikhanum is the wife of Amir Timur and there are many of them, but they were separated by epochs, cultures, traditions and religions. They belonged to different strata of society. Among them were very young girls and grown women. They were very different: regal and commoners, strict and gentle, courageous and feminine, poor and rich, highly educated and intelligent with a natural mind. However, despite all the differences, only they knew how to love and support their children and husbands so selflessly. And this is their genius. But history has shown one thing, the most important thing, that women are somewhat superior to men in the ability to memorize, in verbal ability. They master the practical grammar of the language faster, begin to speak earlier, their vocabulary is richer. They are sincere, practical, intuitive, they socialize into life earlier. They are hardy. Resistant to the hardships of life. They are educators of the nation, the future of the country. In order to systematically organize support for women in Uzbekistan, an "iron notebook" has been formed and introduced in separate lists - a "youth notebook" for unemployed youth and a "women's notebook" for unemployed and no breadwinner women. 
"The iron notebook" included families from vulnerable groups of the population who can count on financial assistance from the state through the makhallas. As you know, a woman is the guarantee of the future of a nation. It is women who educate the nation, the people.. The government adopted a resolution "On additional measures for the social support of women." The Women's Notebook aims to reach many women who have no one to share their problems with, including those who have lost their breadwinner, wandering in a foreign land or returning home, experiencing any difficulties and unable to find their place in life. Women over 30 years old who need social, legal or psychological assistance, as well as employment, are included in the "women's notebook". This is the basis for finding solutions to women's problems.

According to this, women over 30 are included in the "women's notebook" for mahallas in the context of sectors in the following categories:

- unemployed women in need of social protection;

- women in need who have lost their breadwinner; protection;

- women with disabilities of group I who need housing repair;

- women living in non-residential premises, who do not have a residential property on their or co-living family members;

- single women who have one or more children with disabilities I and II groups;

- women in need of medical protection (herself and her family members living together are in a difficult social situation, suffer from chronic or severely disabled diseases, with an unidentified group of disabilities, without sufficient sources of income);

- women in need of legal assistance;

- women in need of psychological counseling (women who have suffered from harassment and violence, who have social problems).

The "Women's Notebook" is kept in the following order. The problems, needs and interests of a woman are studied on a home visit for 15 days in the first month of each half of the year. Problems are identified using a questionnaire, and the identified problems are included in the individual questionnaires of women within a period not exceeding 3 days.

Therefore, a modern, intelligent and nowadays woman still strives to be self-sufficient. In this regard, today special attention is paid to women, girls... Uzbekistan has joined all the main international treaties providing for the legal, social and economic protection of women from any form of discrimination and harassment. Genderoriented laws "On guarantees of equal rights and opportunities for women and men", "On protection of women from oppression and violence", "On the protection of reproductive health of citizens", "On amendments and additions to Article 15 of the 
Family Code", "On amendments to the Labor Code of the Republic of Uzbekistan "- on the removal of restrictions related to the choice by women of previously prohibited forms of work and other gender-asymmetric provisions of labor legislation. Experts from such UN agencies as the UN Development Program, the Population Fund, the Children's Fund, the Office of the High Commissioner for Human Rights, the Office on Drugs and Crime, the International Organization for Migration and the International Labor Organization participated in their development. More than 20 decrees and decrees of the President and government decrees were also adopted. A number of amendments and additions have been made to strengthen efforts to prevent violence against women and domestic violence, and to combat outdated customs. A mandatory gender-legal examination of legislative acts was introduced, aimed at eliminating the inconsistency of the provisions of regulatory legal acts with the principles of gender equality, identifying possible risks of a discriminatory nature in the process of their application. Everyone knows the brilliant phrase that "behind every brilliant man there is a great woman." And it is filled with brilliant content! It was women who from time immemorial inspired men to feats, for their sake men fought in duels, in honor of their beloved they gave names to newly discovered stars, for their sake they went to the ends of the world, achieved great success in creativity, science.... The education and upbringing of women in the present is proved to be a direct and potent leverage in the education of the future generations. Taking into account these qualities and peculiarities of women in Uzbekistan, universities for the second year will introduce a budget quota for girls. The quota was introduced for the 2020/2021 academic year, as well as for the current academic year and since 2008 the girls are already studying at the universities of the country. Since the $4 \%$ quota allows girls to get higher education free of charge. Recommendations to candidates for this quota were issued through the mahalla ministry. The same reforms are envisaged in the New Strategy of Uzbekistan, which states that in 2026, 6000 girls will be admitted to the universities of the country for study on a free basis. On the national strategies in support of women, according to the President of Uzbekistan:
"There are many women in our country who set an example for everyone with their intellect, deep knowledge, great life experience, selfless work and high personal qualities. If, at the upcoming elections to the Oliy Majlis and local kengashs this year, such hardworking and educated women with a broad political outlook can demonstrate their potential and be elected as deputies or senators, then, I am sure, both the state and society will benefit from this."

Today a new structure has been created in the Senate - the Committee on Women and Gender Equality. Its tasks included strengthening legislative activity and parliamentary oversight on women and family issues, considering the employment of women and developing their business skills, promoting women's health, promoting medical culture in families, preventing delinquency and crime among women, human trafficking and 
other negative phenomena such as family breakdown, early marriage and cases of suicide. Today in Uzbekistan there are about 30 normative legal acts to improve the status of women in accordance with the requirements of international standards. These include such laws as "On guarantees of equal rights and opportunities for men and women" and "On the protection of women from harassment and violence" "which were adopted on September 2, 2019. According to the law, violence have been categorised in the sexual, physical, economic and psychological type. And harassment means harassment or any action (and inaction) that degrades the honor and dignity of a woman, for the commission of which there is no administrative or criminal liability.

A victim of oppression and violence has the right to:

- appeal to the authorized bodies and organizations or the court with a statement about the commission of harassment and violence against her or the threat of their commission;

- receiving free legal advice, economic, social, psychological, medical and other assistance in special centers, as well as through a free telephone line;

- appeal to the internal affairs bodies with a requirement to issue a protection order, and in case of violation of the conditions of the protection order - informing them about it;

- going to court with a claim for compensation for material damage caused to her and compensation for moral damage as a result of the perpetrated harassment and violence.

A protection order is issued by the internal affairs bodies for a period not exceeding 30 days from the date of registration. At the moment, regulatory documents are still being developed that will regulate the entire procedure for processing and issuing this protection order.

Evidences show that the social developments in Uzbekistan have brougt to changes in the attitude towards women, by starting to consider women as an influential social force. A protective order gives us the opportunity to ensure the safety of a woman and her minor children. There are cases when conflicts repeatedly arise in the family or there is a complex psycho-emotional situation that puts pressure on a woman and her children, by bringing evidences of increased attempts of suicide or child abandonment. Women do not know where to turn and how to protect themselves.

Every year women in the country play an increasingly important role in public life, occupy leadership positions and do business. According to the IPU's annual report "Women in Parliament" and data from UN-Women, for the first time in history, as of January 2021, the global share of women in national parliaments was more than a quarter $-25.5 \%$. According to the results of the parliamentary elections at the end 
of 2019 , they made up $32 \%$ of the deputies of the Legislative Chamber of the Oliy Majlis, $25 \%$ in the Senate. According to this indicator, Uzbekistan entered the top 50 countries (out of 190), ahead of almost all post-Soviet countries. This testifies to fundamentally new approaches and trends in organizing the activities of the Uzbek parliament. The systematic work of the Parliamentary Commission for monitoring the implementation of the National Goals and Objectives for Sustainable Development for the period up to $\mathbf{2 0 3 0}$ was organized, where the fifth goal is devoted to the tasks of achieving gender equality. Its main tasks include monitoring the implementation of legislation, conducting a critical analysis of the development of those areas that are included in the National Sustainable Development Goals. An important achievement was the creation of the Republican Public Council of Women headed by the Chairman of the Senate of the Oliy Majlis, one of the main tasks of which, along with the full support of women and girls, is to coordinate the implementation of the provisions of the UN Convention on the Elimination of All Forms of Discrimination against Women and the implementation of the Beijing Platform for Action and National Action Plan.

There are three main scientific and practical outcomes related to this research:

- It represents an approach to the prevention of domestic violence, considered as a factor both in society and in the family, is proposed.

- The concept of "respect and honor of a woman" has been introduced into scientific circulation, meaning behavior at all levels of society and the formation in this way of a culture in society with a high tolerance to violence.

- The characteristic features of domestic violence are revealed, the law, regulatory legal acts, which include the legal framework, are analyzed, where the issuance of orders of protection for such relationships in families is considered. The same is valid for the country's strategy to protect the rights of women from violence. In accordance with the Law of the Republic of Uzbekistan "On guarantees of equal rights and opportunities for women and men", recommendations have also been developed for the establishment of an Advisory Council on Gender Equality in all ministries and departments and in labor collectives, advisory councils have been created. Thus, the law "On the Protection of Women from Harassment and Violence" creates a legal basis for providing victims with protection by the internal affairs bodies, and also allows to systematize the process of providing them with various kinds of assistance from the state. Although violence against women is illegal under current criminal law, there have been no previous regulations on the registration of cases of gender-based violence or measures recommended to provide protection and assistance to victims. 


\section{Conclusions}

Ensuring equal rights and opportunities for women and men in the social, economic and political spheres is one of the main factors in strengthening peace and economic stability in our society. Taking this into account, the Senate of the Oliy Majlis at the fifteenth plenary session on May 28 approved the "Strategies for achieving gender equality in the Republic of Uzbekistan in 2020-2030." In 81 ministries and departments, a reserve of more than 15 thousand personnel has been formed, consisting of advanced and educated women and for the first time in the history of Uzbekistan, the number of women in the national parliament reached the level (32\%) - the country ranks 37th among 190 countries in this indicator. According to the head of the Senate, the proportion of women in leadership positions has reached $27 \%$. Six women were appointed as khokims, one as an ambassador. An innovation of these reforms is the system of covering the costs of educating needy girls who have lost their parents or one of them, single women who do not have a breadwinner, the number of grants for girls from low-income families for admission to higher educational institutions has been doubled. In addition, in the World Bank's Women, Business and Law Index in 2020, Uzbekistan was included in the list of 27 countries that "implemented significant reforms in the field of women's rights and gender equality", rose 5 positions and took 134th place out of 190. In September 2020, the UN said that no country in the world in a quarter of a century has come close to the full implementation of the Beijing Declaration on the Rights of Women. In the world, only about $25 \%$ of government officials and managers are women, the remaining $75 \%$ are still men. 16 women occupy leadership positions in the Ministry of Internal Affairs, 6 women are appointed by khokims and 1 woman is an ambassador. In addition, there are about 1,500 women in leadership positions at various levels. According to the results of the elections to the Oliy Majlis and local Kengashes in December 2019, women-deputies accounted for $32 \%$ of the total number of deputies of the Legislative Chamber, women-senators - $25 \%$ of members of the Senate. In local Kengashes, the number of women is $25.6 \%$. According to this indicator, the parliament of Uzbekistan ranks 44th among 190 parliaments of the world. The practice has been introduced of allocating grants to vocational education institutions at the expense of the State Fund for the Promotion of Employment to finance the costs of vocational training for women living in lowincome families. In order to strengthen ties with foreign organizations, jointly with such international organizations as UNICEF, UNFPA, UN, World Bank, Asian Development Bank, USAID, OSCE, EBRD, on the basis of bilateral proposals, annual joint plans are also being developed and implemented.

A series of meetings of associations, institutions, colleges, dealing with women and youth issues, round tables with young people, students and women in makhallas, universities and other auditoriums about gender policy and the protection of the rights of women, are considered as tools of sensibilisation, inclusion and development in pursuing the humanistic principle "The interests of mankind are above all". 


\section{Bibliography}

1. Bartholini, Ignazia. "Some consideration about the gender violence in two States of Eastern and Western Europe." Academicus International Scientific Journal 6.11 (2015): 142-153.

2. Council of Europe Convention on Preventing and Combating Violence against Women and Domestic Violence. https://docs.cntd.ru/document/420206767

3. Declaration on the Elimination of Violence against Women. Adopted by General Assembly resolution 48/104 of December 20, 1993. https://www.un.org/ru/ documents/decl_conv/declarations/violence.shtml

4. Law of the Republic of Uzbekistan "On guarantees of equal rights and opportunities for women and men.", September 2, 2019, No. 3PY-562 (National database of legislation, 03.09.2019, No. 03/19/562/3681)

5. Resolution of the Cabinet of Ministers of the Republic of Uzbekistan "On additional measures for the social support of women." Tashkent, January 8, 2021, No. 2

6. Resolution of the Cabinet of Ministers of the Republic of Uzbekistan "On additional measures for social support of families, women and youth in need of material assistance and support." Tashkent, April 28, 2021, No. 250

7. Robo, Marsela. "Social inclusion and inclusive education." Academicus International Scientific Journal 10 (2014): 181-191.

8. Rusi, Nadia. "Aspects of government policies in the fields of economy and entrepreneurship from the gender viewpoint." Academicus International Scientific Journal 6.11 (2015): 32-39.

9. The Law of the Republic of Uzbekistan "On the Protection of Women from Oppression and Violence". Tashkent, September 2, 2019, No. 3Py-561. (National database of legislation, 03.09.2019, No. 03/19/561/3680)

10. Vrajolli, Marigonë. "Role and participation of women in the establishment and implementation of international security policies." Academicus International Scientific Journal 9.17 (2018): 54-61. 